\title{
REAÇÃO DE LINHAGENS DE FEIJOEIRO AO FUNGO Fusarium oxysporum f. sp. phaseoli EM CONDIÇÕES CONTROLADAS
}

\author{
Reaction of common bean lines to Fusarium oxysporum f. sp. phaseoli in controlled conditions
}

\author{
Mônica Juliani Zavaglia Pereira', Magno Antonio Patto Ramalho², Ângela de Fátima Barbosa Abreu²
}

\begin{abstract}
RESUMO
Entre os patógenos que mais contribuem para a redução da produtividade do feijoeiro no Brasil está o Fusarium oxysporum f. sp. phaseoli. O emprego de cultivares resistentes é o controle mais eficaz para esse patógeno. Conduziu-se este trabalho, com o objetivo de avaliar linhagens de feijoeiro (Phaseolus vulgaris L.) do banco de germoplasma da Universidade Federal de Lavras (UFLA), quanto a reação ao Fusarium oxysporum f. sp. phaseoli e, ao mesmo tempo, estimar os parâmetros genéticos e fenotípicos que possam auxiliar em futuros programas de melhoramento para esse caráter. Foram avaliadas 367 linhagens em dez experimentos. As testemunhas 'Carioca' (suscetível) e 'Carioca MG' (resistente) foram utilizadas em todos os experimentos. O delineamento utilizado foi inteiramente ao acaso, com cinco repetições e parcelas de uma planta por vaso. As inoculações foram realizadas segundo a metodologia de corte e imersão de raízes na suspensão de esporos do fungo e as avaliações realizadas aos 21 dias após a inoculação com base no índice de severidade da doença empregando-se notas de 1 (plantas sem sintomas) a 9 (plantas mortas).Das linhagens do banco de germoplasma da Universidade Federal de Lavras (UFLA) avaliadas, 36,5\% foram resistentes ao Fusarium oxysporum f. sp. phaseoli. Entre as resistentes, a maioria foi linhagens obtidas antes de 1990. Das 18 linhagens dos experimentos de VCU, do período de $2005 / 06$, apenas quatro foram suscetíveis. A estimativa da herdabilidade $\left(h^{2}\right)$ foi elevada $\left(h^{2}=87 \%\right)$, indicando que, a princípio, o caráter é de fácil seleção.
\end{abstract}

Termos para indexação: Linhagens resistentes, murcha-de-fusarium, Phaseolus vulgaris.

\begin{abstract}
Among the pathogens that most contribute for reducing the productivity of beans in Brazil is the Fusarium oxysporum f. sp. phaseoli. The use of resistant cultivars is the most effective control for this pathogen. The aim of this study was to evaluate germoplasm bean (Phaseolus vulgaris L.) lines of the Federal University of Lavras (UFLA) as the reaction to the Fusarium oxysporum f. sp. phaseoli and at the same time, to estimate the genetic and phenotypic parameters that could help in future programs of improvement for this character. Three hundred and sixty seven lines were evaluated in ten experiments. The controls' Carioca'(susceptible) and 'Carioca MG'(resistant) were used in all experiments. The experimental design used was a entirely randomized one, with five replicates and plots of one plant per pot. The inoculations were carried out following the method of cutting and dumping of roots in the suspension of spores of the fungus and the assessments conducted at 21 days after inoculation based on the index of severity of the disease employing up notes of 1 (plants without symptoms) to 9 (dead plants). Among the lines of germoplasm bank of the Federal University of Lavras (UFLA) assessed, 36.5\% were resistant to Fusarium oxysporum f. sp. phaseoli. Among the resistance, most of the lines were obtained before 1990: out of the 18 lines of the experiments of VCU evaluated in 2005/06, only four were susceptible. The estimate of heritability $\left(\mathrm{h}^{2}\right)$ was high $\left(\mathrm{h}^{2}=87 \%\right)$, indicating that, in principle, the character is of easy selection.
\end{abstract}

Index termes: Resistant lines, fusarium wilt, Phaseolus vulgaris.

(Recebido em 24 de janeiro de 2008 e aprovado em 20 julho de 2008)

\section{INTRODUÇÃO}

No cultivo sucessivo do feijoeiro (Phaseolus vulgaris L.) sob pivô central, a ocorrência de doenças está inviabilizando a economicidade do empreendimento no Brasil. A cada safra, a produtividade reduz, mesmo com o uso mais intensivo de defensivos agrícolas. Entre as doenças que contribuem para a redução da produtividade está a murcha-de-fusarium, cujo agente etiológico é o fungo Fusarium oxysporum f. sp. phaseoli.

Sob condições de temperatura mais elevada associada à alta umidade a doença causa danos expressivos. Sua atuação depende também da concentração de inóculo, das condições de estresse e de drenagem deficiente do solo. O patógeno já foi identificado em todas as regiões produtoras de feijão do mundo (PASTOR-CORRALES; ABAWI, 1987). Perdas no

\footnotetext{
1Universidade Federal de Lavras/UFLA - Departamento de Biologia/DBI - Cx. P. 3037 - 37200-000 - Lavras, MG - mjzpereira@yahoo.com.br 2Universidade Federal de Lavras/UFLA - Departamento de Biologia/DBI - Lavras, MG
} 
rendimento de grãos de até $80 \%$ já foram registradas na Costa Rica (ECHANDI, 1967) e de 30\% nos Estados Unidos (CRAMER et al., 2003).

Entre as medidas de controle, o emprego de cultivares resistentes é o mais eficaz. Alguns trabalhos já foram realizados, especialmente no período de 1985 a 1998, visando à identificação de fontes de resistência (PASTORCORRALES; ABAWI, 1987; BALARDIN et al., 1990; PIZA, 1993; NASCIMENTO et al., 1995; RAVAet al., 1996; ROCHA JÚNIOR et al., 1998). Embora a maioria das linhagens avaliadas tenha apresentado reação intermediária ou de suscetibilidade, algumas foram resistentes ao patógeno.

Nos 32 anos do programa de melhoramento do feijoeiro da Universidade Federal de Lavras (UFLA), foram obtidas centenas de linhagens, especialmente de grãos tipo 'carioca' e com bom potencial produtivo (MATOS et al., 2007). As linhagens resultantes desse programa foram submetidas à caracterização quanto à reação a patógenos importantes na região (ABREU et al., 2003; AMARO et al., 2007; RAMALHO et al., 2007). Contudo, ainda são restritos os trabalhos de avaliação realizados com relação à reação do feijoeiro à murcha-de-fusarium.

Desse modo, foi realizado o presente trabalho, com o objetivo de avaliar as linhagens do banco de germoplasma da UFLA em relação à reação a Fusarium oxysporum $\mathrm{f}$. sp. phaseoli e, ao mesmo tempo, estimar parâmetros genéticos e fenotípicos que possam auxiliar em futuros programas de melhoramento para esse caráter.

\section{MATERIAL E MÉTODOS}

Os experimentos foram conduzidos no Departamento de Biologia, área de Genética e Melhoramento de Plantas, da Universidade Federal de Lavras (UFLA), em Lavras, MG.

Foram avaliadas 349 linhagens de feijoeiro, provenientes do banco de germoplasma do setor de Genética e Melhoramento de Plantas da UFLA e 18 linhagens do experimento de valor de cultivo e uso (VCU), conduzido em Minas Gerais, no período de 2005/2006, pela Universidade Federal de Lavras (UFLA), Universidade Federal de Viçosa (UVF), Empresa Brasileira de Pesquisa Agropecuária (Embrapa Arroz e Feijão) e Empresa de Pesquisa Agropecuária de Minas Gerais (Epamig). As avaliações foram realizadas no período de janeiro de 2006 a março de 2007, totalizando dez experimentos. Em todos os experimentos, as linhagens 'Carioca' e 'Carioca MG' foram utilizadas como testemunhas suscetíveis e resistentes, respectivamente. $\mathrm{O}$ delineamento utilizado foi inteiramente ao acaso, com cinco repetições e parcelas de uma planta por vaso.
As linhagens foram inoculadas com o isolado Fop 01 de Fusarium oxysporum f. sp. phaseoli, coletado de plantas de feijoeiro com a doença, no campo experimental do Departamento de Biologia e, após, conservado em tubos de ensaio contendo meio de cultura BDA, imersos em óleo mineral e armazenados em $\mathrm{BOD}$, à temperatura de $24^{\circ} \mathrm{C} \pm 1^{\circ}$ C. Para a produção do inóculo, segmentos do meio contendo o fungo foram repicados para placas de Petri contendo os meios de BDA e de extrato de semente de feijão dextrose ágar (ESFDA) (RIBEIRO; FERRAZ, 1984). As placas foram mantidas em BOD, durante 10 dias, em temperatura de $24^{\circ} \mathrm{C} \pm 1^{\circ} \mathrm{C}$, sob iluminação contínua. A suspensão de esporos foi preparada minutos antes de cada inoculação, sendo utilizada concentração de $1 \times 10^{6}$ conídios/ml (macro e microconídios).

A semeadura das linhagens foi realizada em bandejas de isopor de 128 células, contendo substrato Plantmax $^{\circledR}$ hortaliças, sendo colocadas em casa de vegetação para germinação de sementes e crescimento das plantas. Quando as plantas estavam com 9-10 dias após a semeadura (primeiro par de folhas unifolioladas completamente expandido), foram realizadas as inoculações, pela metodologia de imersão de raízes, previamente cortadas, em suspensão de esporos, conforme descrito por Pastor-Corrales e Abawi (1987). As plantas, após a inoculação, foram transplantadas para vasos plásticos contendo substrato Plantmax- hortaliças e mantidas em câmara climatizada, com temperatura de $22^{\circ}$ $\mathrm{C} \pm 2^{\circ} \mathrm{C}$ e fotoperíodo de 12 horas, ou em casa de vegetação, durante o período das avaliações. A cada dois dias, as plantas eram regadas e, dez dias após a inoculação, receberam 1,0 g de adubo da formulação 8-28-16 de NPK.

Em todos os experimentos, as avaliações foram realizadas aos 21 dias após a inoculação (DAI), com base no índice de severidade da doença desenvolvido no CIAT (PASTOR-CORRALES; ABAWI, 1987), no qual: 1= nenhum sintoma foliar ou vascular; $3=$ de $1 \%$ a $10 \%$ de folhas sintomáticas, suave murchamento de plantas e descoloração vascular no hipocótilo; $5=11 \%$ a $25 \%$ de folhas sintomáticas, moderada murcha nas plantas e descoloração vascular extensa até o primeiro nó; $7=26 \%$ a $50 \%$ de folhas sintomáticas, severa murcha de plantas e descoloração vascular por toda a haste e pecíolo e $9=$ planta morta. As linhagens com média de 1,0 a 3,0 foram consideradas resistentes, de 3,1 a 6,0 intermediárias e 6,1 a 9,0 suscetíveis (PASTOR-CORRALES; ABAWI, 1987; SALGADO; SCHWARTZ, 1993; ELENA; PAPAS, 2002).

As notas de severidade foram transformadas para raiz quadrada $(\mathrm{x}+0,5) \mathrm{e}$, posteriormente, submetidas à análise de variância dos experimentos combinados, com 
testemunhas comuns, segundo procedimento semelhante ao apresentado por Pimentel-Gomes (1990), utilizando o programa SAS 8.0 (SAS, 1999), adotando o seguinte modelo:

$\mathrm{Y}_{\mathrm{ijk}}=\mathrm{m}+\mathrm{t}_{\mathrm{i}}+\mathrm{c}_{\mathrm{j}}+\mathrm{g}_{\mathrm{k}}+\mathrm{cg}_{(\mathrm{jk})}+\mathrm{e}_{(\mathrm{ijk})}$

Emque:

$\mathrm{m}$ : média geral do experimento; $\mathrm{t}_{\mathrm{i}}$ : efeito das linhagens $\mathrm{i}$, $(i=1,2,3, \ldots, 369) ; c_{j}$ : efeito das testemunhas comuns a todos os experimentos $(\mathrm{j}=1,2) ; \mathrm{g}_{\mathrm{k}}$ : efeito dos experimentos $\mathrm{k},(\mathrm{k}=1,2, \ldots, 10) ; \mathrm{cg}_{(\mathrm{jk})}$ : efeito da interação entre as testemunhas comuns e os experimentos; $\mathrm{e}_{(\mathrm{ijk})}$ : erro experimental associado à observação $\mathrm{Y}_{\mathrm{ijk}}$, tendo $\mathrm{e}_{\mathrm{ijk}}$ $\cap \mathrm{N}\left(0, \sigma_{\mathrm{e}}^{2}\right)$.

Os componentes de variância e a herdabilidade foram obtidas pelos seguintes estimadores:

Variância genética entre linhagens $\left(\sigma_{\mathrm{L}}^{2}\right)=\left(\mathrm{QM}_{\text {Linhagens }}-\right.$ $\left.\mathrm{QM}_{\text {Erro }}\right) / \mathrm{r}$

Variância fenotípica entre média das linhagens $\left(\sigma^{2} \overline{\mathrm{F}}\right)=$ $\mathrm{QM}_{\text {Linhagens }} / \mathrm{r}$

Herdabilidade para a seleção na média das linhagens $\left(\mathrm{h}^{2}\right)=$ $\left(\mathrm{QM}_{\text {Linhagens }}-\mathrm{QM}_{\text {Erro }}\right) / \mathrm{QM}$ Linhagens

Em que;

QM: o quadrado médio obtido na análise de variância; r: o número de repetições.

Os intervalos de confiança para a herdabilidade foram estimados utilizando-se a expressão de Knapp et al. (1985).

$$
\begin{aligned}
& \mathrm{LI}=\left\{1-\left[\left(\mathrm{QM}_{\text {Linhagens }} / \mathrm{QM}_{\text {Erro }}\right) \mathrm{F}_{1-\mathrm{a} / 2} ;{ }_{\text {GLErro; GLLinhagens }}\right]^{-1}\right\} \\
& \mathrm{LS}=\left\{1-\left[\left(\mathrm{QM}_{\text {Linhagens }} / \mathrm{QM}_{\text {Erro }}\right) \mathrm{F}_{\mathrm{a} / 2} ; \text { GLErro; GLLinhagens }\right]^{-1}\right\}
\end{aligned}
$$

Em que:

F: valor tabelado da distribuição F de Snedecor a partir dos graus de liberdade de linhagens e do erro e do nível de significância $(\alpha=0,05)$.

\section{RESULTADOS E DISCUSSÃO}

A eficiência da procura por linhagens resistentes aos patógenos em um programa de melhoramento de plantas depende da precisão em que as avaliações são realizadas. A precisão experimental pode ser avaliada por alguns procedimentos. O mais utilizado é a estimativa do coeficiente de variação experimental (CV). Observa-se, na Tabela 1, que o CV nas análises de variância combinada foi médio ( $C V=24,4 \%)$, se comparado aos normalmente obtidos com a cultura do feijoeiro para a produtividade de grãos (CV=19,7\%), por exemplo (MATOS et al., 2007). Nesse contexto, deve ser mencionado que a avaliação da murchade-fusarium foi efetuada por meio de uma escala de notas variando de 1 a 9 , o que pode ter contribuído para a maior estimativa do erro. Contudo, mesmo com a precisão experimental obtida foi possível classificar as linhagens com relação à resistência ou não ao patógeno.

Constatou-se, como era esperado, dadas as diferentes origens das linhagens, diferença significativa entre elas $(\mathrm{P} \leq 0,01)$, com relação à resposta à inoculação com Fusarium (Tabela 1). Não se constatou diferença significativa entre os experimentos e nem a interação 'testemunhas comuns x experimentos'. Nesse contexto, deve ser salientado que as duas testemunhas, uma resistente, a 'Carioca MG' e uma suscetível, a 'Carioca', apresentaram comportamento coincidente de reação em diversos experimentos (PEREIRA et al., 2008). Esse resultado é importante porque é difícil avaliar um grande número de linhagens, como ocorreu nesse caso, de uma só vez. O comportamento das testemunhas mostrou que a avaliação por etapas, com posterior análise combinada, é eficiente na identificação de linhagens de feijoeiro resistentes ao Fusarium.

Uma boa metodologia de avaliação de linhagens, com relação a patógenos, é aquela que possibilita discriminar bem todos os genótipos. Isso ocorreu neste trabalho, pois as linhagens receberam notas variando de 1,0 a 9,0 (Figura 1), ou seja, toda a amplitude de variação de notas, com média de 5,28. Trabalhos prévios mostraram a eficiência dessa metodologia em discriminar as linhagens com relação à severidade do $F$. oxysporum $\mathrm{f}$. sp. phaseoli em feijoeiro (PEREIRA et al., 2008).

Outro questionamento na seleção é qual o nível máximo de severidade do patógeno para se considerar uma linhagem como resistente. Na literatura, em avaliações com outros patógenos em feijoeiro, utilizando escala de notas variando de 1 a 9, são consideradas resistentes as linhagens e ou plantas com severidade igual ou inferior a 3 (SARTORATO; THUNG, 2002; RAGAGNIN et al., 2003). Utilizando esse critério, constatou-se que 36\% (134 linhagens) podem ser consideradas como resistentes (Figura 1). Salienta-se, ainda, que mais de $50 \%$ das linhagens classificadas como resistentes receberam nota 1,0; ou seja, ausência total de doença.

Como já mencionado, na literatura foram encontrados alguns relatos de avaliação de linhagens, com 
relação ao F. oxysporum f. sp. phaseoli. A maioria deles, entretanto, avaliou número restrito de linhagens, principalmente no período de 1985 a 1998 (PASTORCORRALES; ABAWI, 1987; BALARDIN et al., 1990; PIZA, 1993; NASCIMENTO et al., 1995; RAVA et al., 1996; ROCHA JÚNIOR et al., 1998). Embora houvesse diferença entre os resultados obtidos, na maioria das avaliações foram encontradas linhagens resistentes, porém, em menor proporção que a constatada no presente trabalho. A maior proporção foi observada por Rava et al. (1996), 50\% de linhagens resistentes. Contudo, foram avaliadas apenas 12 linhagens. Rocha Júnior et al. (1998), por exemplo, avaliaram 169 linhagens utilizando metodologia semelhante à adotada nesse trabalho e constataram, 30 dias após a inoculação, que $91,7 \%$ delas foram suscetíveis.

Outro fato interessante é a elevada quantidade de linhagens resistentes no grupo das mais antigas, ou seja, obtidas antes de 1990, em relação às mais recentes. Das 134 linhagens classificadas como resistentes, apenas 27 foram obtidas recentemente, ou seja, 7,34\% do número total de linhagens avaliadas. É comum, na cultura do feijoeiro, que os agricultores de subsistência não adquiram sementes periodicamente (SENA et al., 2008). Eles reutilizam os seus grãos como sementes, por várias gerações, o que originou muitas cultivares "landraces". Algumas delas foram avaliadas no presente trabalho e receberam nota 1 (resistentes), como, por exemplo, 'Manteigão Fosco', 'Hulk' e 'Baetão' entre outras (Tabela 2). É bem provável que os agricultores tenham selecionado plantas resistentes a esse patógeno, não utilizando sementes colhidas de plantas doentes para as futuras semeaduras. Por essa razão, muitas linhagens existentes no Banco de Germoplasma da UFLA, que foram obtidas de coletas, são resistentes.

Tabela 1 - Resumo da análise de variância combinada das notas de severidade do Fusarium oxysporum f. sp. phaseoli em linhagens de feijoeiro.

\begin{tabular}{lccc}
\hline \multicolumn{1}{c}{$\mathrm{FV}$} & $\mathrm{GL}$ & $\mathrm{SQ}$ & $\mathrm{QM}^{*}$ \\
\hline Experimentos & 9 & 2,39 & $0,27^{\mathrm{NS}}$ \\
Linhagens & 357 & 852,78 & $2,39^{* *}$ \\
Testemunhas comuns & 1 & 51,71 & $51,71^{* *}$ \\
Test comuns x experimentos & 9 & 1,93 & $0,21^{\mathrm{NS}}$ \\
Erro & 1548 & 461,87 & 0,30 \\
\hline Média* & & 2,24 & \\
$\mathrm{CV}(\%)^{*}$ & & 24,40 & \\
$\mathrm{R}^{2}(\%)^{*}$ & & 68,85 & \\
\hline
\end{tabular}

* dados transformados em raiz quadrada $(\mathrm{x}+0,5)$.

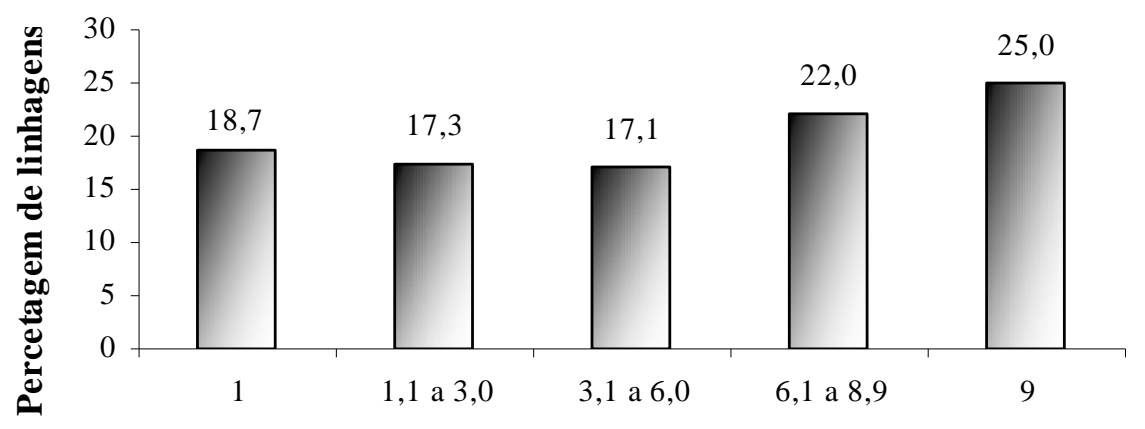

\section{Notas de severidade}

Figura 1 - Distribuição de frequência das notas de severidade de linhagens de feijoeiro ao fungo Fusarium oxysporum f. sp. phaseoli. 
Tabela 2 - Linhagens de feijoeiro consideradas resistentes e notas de severidade quanto a reação a Fusarium oxysporum f. sp. phaseoli.

\begin{tabular}{|c|c|c|c|c|c|}
\hline Linhagem & Nota & Linhagem & Nota & Linhagem & Nota \\
\hline ESAL 588 & 1,0 & IAPAR 16 & 1,0 & * OP-NS-331 & 2,2 \\
\hline CIAT 437 & 1,0 & $\mathrm{R}-17$ & 1,0 & AN 910408 & 2,6 \\
\hline ESAL 565 & 1,0 & Pintado & 1,0 & ESAL 619 & 2,6 \\
\hline ESAL 615 & 1,0 & ESAL 656 & 1,0 & CNF 246 & 2,6 \\
\hline ESAL 547 & 1,0 & Feijão Chileno & 1,0 & TU x Carioca & 2,6 \\
\hline ESAL 583 & 1,0 & ESAL 655 & 1,0 & CIAT 270 & 2,6 \\
\hline ESAL 566 & 1,0 & ESAL 607 & 1,0 & Cai Folha & 2,6 \\
\hline Aroana & 1,0 & ESAL 651 & 1,0 & ESAL 654 & 2,6 \\
\hline ESAL 589 & 1,0 & ESAL 611 & 1,0 & ESAL 647 & 2,6 \\
\hline Milionario & 1,0 & CNF 261 & 1,0 & FT Tarumã & 2,6 \\
\hline CIAT 249 & 1,0 & A-242 & 1,0 & Feijão Favinha & 2,6 \\
\hline CIAT 57 & 1,0 & Dade & 1,0 & ESAL 625 & 2,6 \\
\hline Moruna Rosa & 1,0 & Coleta 185 & 1,0 & ESAL 606 & 2,6 \\
\hline BAT 41 & 1,0 & $\mathrm{H}-4-23$ & 1,0 & ESAL 592 & 2,6 \\
\hline DOR 95 & 1,0 & VP-11 & 1,0 & ESAL 597 & 2,6 \\
\hline DOR 196 & 1,0 & VP-12 & 1,0 & ESAL 629 & 2,6 \\
\hline Bolinha & 1,0 & VP-9 & 1,0 & ESAL 585 & 2,6 \\
\hline Perry Marrow & 1,0 & VP-8 & 1,0 & ESAL 630 & 2,6 \\
\hline Rico Pardo 896 & 1,0 & * CV-46 & 1,0 & D-245 & 2,6 \\
\hline ESAL 618 & 1,0 & * CNFC-8075 & 1,0 & VP-1 & 2,6 \\
\hline ESAL 642 & 1,0 & $* \mathrm{VC}-9$ & 1,0 & VP-2 & 2,6 \\
\hline ESAL 535 & 1,0 & Eriparsa 1 & 1,2 & MA-I-8-13 & 2,6 \\
\hline ESAL 526 & 1,0 & CIAT A-296 & 1,2 & $\mathrm{CV}-31$ & 2,6 \\
\hline JALO & 1,0 & ESAL 586 & 1,4 & $\mathrm{CV}-21$ & 2,6 \\
\hline Feijao Bagajo & 1,0 & ESAL 568 & 1,4 & VC-1 & 2,6 \\
\hline ESAL 541 & 1,0 & ESAL 633 & 1,4 & VP-4 & 2,6 \\
\hline ESAL 576 & 1,0 & Mulatinho 106 & 1,4 & VI $5500 \mathrm{P}$ & 2,6 \\
\hline Capixaba precoce & 1,0 & ESAL 632 & 1,4 & * MAI-2-5 & 2,6 \\
\hline CNF 266 & 1,0 & ESAL 601 & 1,4 & * CNFC-8959 & 2,6 \\
\hline ESAL 533 & 1,0 & ESAL 626 & 1,4 & ESAL 644 & 2,8 \\
\hline CNF 243 & 1,0 & $\mathrm{VC}-10$ & 1,4 & $* \mathrm{VC}-3$ & 2,8 \\
\hline Baetao & 1,0 & ESAL 569 & 1,6 & ESAL 621 & 3,0 \\
\hline H-87 & 1,0 & ESAL 617 & 1,8 & ESAL 636 & 3,0 \\
\hline ESAL 644 & 1,0 & PUAD III & 1,8 & ESAL 657 & 3,0 \\
\hline ESAL 609 & 1,0 & IAPAR 31 & 1,8 & ESAL 610 & 3,0 \\
\hline ESAL 533 & 1,0 & ESAL 516 & 1,8 & Mineiro Precoce & 3,0 \\
\hline Batatinha & 1,0 & Diacol Calima & 1,8 & Aporé & 3,0 \\
\hline Hulk & 1,0 & IAPAR 14 & 1,8 & $* \mathrm{VC}-12$ & 3,0 \\
\hline ESAL 550 & 1,0 & ESAL 640 & 1,8 & & \\
\hline BAT 304 & 1,0 & Z-9 & 1,8 & Carioca $^{1}$ & 8,4 \\
\hline
\end{tabular}

Ciênc. agrotec., Lavras, v. 35, n. 5, p. 940 -947, set./out., 2011 
Tabela 2 - Continuação.

\begin{tabular}{lllll}
\hline Negrito & 1,0 & $*$ RC-I-8 & 1,8 & Carioca MG $^{2}$ \\
ESAL 530 & 1,0 & $*$ VC-6 & 1,8 & \\
Rio Tibagi & 1,0 & $*$ VC-8 & 1,8 & \\
CIAT 250 & 1,0 & $*$ VC-7 & 2,0 & \\
Goiano Precoce & 1,0 & ESAL 563 & 2,2 & \\
Manteigão fosco & 1,0 & ESAL 579 & 2,2 & \\
Flor de Mayo & 1,0 & $*$ VC-11 & 2,2 & \\
\hline
\end{tabular}

* Linhagens do experimento de Valor de Cultivo e Uso (VCU) 2005/06; ${ }^{1}$ testemunha suscetível; ${ }^{2}$ testemunha resistente.

Deve ser enfatizado que, muitas linhagens recentemente obtidas, incluindo as que fizeram parte dos experimentos de VCU de 2005/06, foram resistentes, ou seja, das 18 linhagens VCU 2005/06, 13 foram resistentes. Considerando que nenhum trabalho do programa de melhoramento do feijoeiro realizado no estado de Minas Gerais foi direcionado para esse patógeno, é surpreendente o fato de 134 linhagens terem sido identificadas como resistentes. Depreende-se que alguma seleção "inconsciente" foi realizada contra esse patógeno ao longo do tempo. Entretanto, esse é um patógeno que, normalmente, causa a morte prematura das plantas, sobretudo no período de enchimento de grãos. Em consequência, os indivíduos afetados quase não produzem grãos. Como a seleção, ao longo do tempo, vem sendo realizada predominantemente para a produtividade de grãos, indiretamente foram selecionadas linhagens e ou indivíduos resistentes ao patógeno, uma vez que ele é de ocorrência frequente nas áreas experimentais. A eficiência da seleção indireta para a resistência ao Colletotrichum lindemuthianum, utilizando a produtividade de grãos, já foi constatada (ABREU et al., 2003).

Algumas linhagens utilizadas como fonte de resistência a outros patógenos de importância (Pseudocercospora griseola e Colletotrichum lindemuthianum) foram suscetíveis quanto à reação ao Fusarium. Entre elas, a G2333, que possui três genes de resistência ao $C$. lindemuthianum (Co- $4^{2}, \mathrm{Co}-5$ e Co-7), sendo que o Co- $4^{2}$ confere resistência a todas as raças do patógeno identificadas no Brasil (YOUNG et al., 1998). Nesse experimento, a G2333 foi classificada como suscetível ao Fusarium, com nota de severidade de 6,2.

A cultivar Carioca, padrão de suscetibilidade ao patógeno, foi recomendada há mais de trinta anos (ALMEIDA et al., 1977). Essa cultivar foi muito importante para a cultura do feijoeiro na década de 1970, por ter proporcionado aumento significativo na produtividade de grãos da cultura, sendo tolerante a vários estresses abióticos, porém com elevada suscetibilidade ao Fusarium. Posteriormente, em programas de melhoramento do feijoeiro foram selecionados os caracteres favoráveis da 'Carioca' em vários cruzamentos, com o intuito de obter novas linhagens que a substituíssem vantajosamente. Foram obtidas linhagens que associaram grãos tipo carioca e resistência a alguns patógenos. Um cruzamento com sucesso para a resistência a $C$. lindemuthianum, por exemplo, foi entre as linhagens Carioca 80 x Rio Tibagi, que originou a Carioca MG. Vale ressaltar que a Carioca 80 foi suscetível ao Fusarium no presente trabalho (nota 9,0) e a Rio Tibagi resistente (nota 1,0).

Vale ressaltar também que algumas linhagens de feijoeiro recomendadas para semeadura em Minas Gerais e outros Estados apresentam elevada suscetibilidade ao patógeno. Entre elas, as cultivares de feijão-preto 'Valente', 'Uirapuru' e 'Meia Noite' foram classificadas com nota 9,0 de severidade a Fusarium na presente avaliação e foram recomendadas, sobretudo, pela excelente arquitetura da planta. Portanto, essas cultivares não devem ser indicadas para condições em que há relatos de ocorrência da murchade-fusarium.

Muitas outras linhagens, com grãos tipo carioca, estão disponíveis atualmente como fontes de resistência ao Fusarium. A OPNS-331, que foi recomendada para o Estado de Minas Gerais, com o nome de BRSMG Majestoso, é um exemplo de cultivar resistente ao Fusarium. Merecem destaque também todas as linhagens do VCU carioca, já mencionadas, que foram resistentes ao Fusarium (Tabela 2).

A herdabilidade $\left(h^{2}\right)$, que estima a proporção da variância fenotípica que é decorrentes das causas genéticas, foi elevada $\left(h^{2}=87 \%\right)$, indicando que, a princípio, é esperado sucesso com a seleção para o caráter (Tabela 3). Nesse caso, como se avaliaram linhagens, a variância genética encontrada é toda de natureza aditiva (SOUZA JUNIOR, 1989; RAMALHO et al., 1993). Vale ressaltar que o intervalo de confiança da estimativa de $\mathrm{h}^{2}$ foi pequeno. 
Tabela 3 - Estimativas dos parâmetros genéticos e fenotípicos para as notas de severidade de Fusarium oxysporum $\mathrm{f}$. sp. phaseoli, em linhagens de feijoeiro.

\begin{tabular}{lc}
\hline Parâmetros & Estimativa* \\
\hline Variância genética entre linhagens $\left(\sigma_{\mathrm{L}}^{2}\right)$ & 0,42 \\
Variância fenotípica entre média das linhagens $\left(\sigma^{2} \bar{F}\right)$ & 0,48 \\
Herdabilidade para seleccão na média das linhagens $\left(\mathrm{h}^{2}\right)$ & 0,87 \\
Limite Inferior de $\mathrm{h}^{2}$ & 0,85 \\
Limite Superior de $\mathrm{h}^{2}$ & 0,89 \\
\hline
\end{tabular}

* dados transformados em raiz quadrada $(\mathrm{x}+0,5)$.

$\mathrm{O}$ único relato de estimativa de $\mathrm{h}^{2}$ para esse caráter em feijoeiro foi o de Cross et al. (2000), que também obtiveram estimativa elevada $\left(h^{2}=85 \%\right)$, utilizando regressão entre a média dos genitores e a média da geração $\mathrm{F}_{2}$.

Embora a avaliação da severidade de Fusarium seja subjetiva, ou seja, por escala de notas, uma estimativa alta de $h^{2}$ era esperada, uma vez que, ao que tudo indica, a resistência a esse patógeno deve ser controlada por poucos genes. Há relatos de que o alelo dominante do gene Fop 1, confere resistência à raça 2, também denominada de 'Brasileira', de Fusarium (RIBEIRO; HAGEDORN, 1979). Também utilizando linhagens brasileiras, Pereira et al. (2009) evidenciaram que o controle é monogênico. Contudo, a existência de outros genes de efeito menor não deve ser descartada, em razão da ocorrência de ampla variação na expressão fenotípica, conforme verificado por Pereira et al. (2008). É evidente que parte dessa variação é de natureza ambiental, mas variação genética certamente deve ocorrer.

\section{CONCLUSÃO}

Das linhagens do banco de germoplasma da Universidade Federal de Lavras (UFLA) avaliadas, 36,5\% são resistentes ao Fusarium oxysporum f. sp. phaseoli e a herdabilidade do caráter é alta, indicando possibilidade de sucesso na seleção para a resistência ao fungo.

\section{AGRADECIMENTOS}

Os autores agradecem ao $\mathrm{CNPq}$ pelo auxílio financeiro para a condução do trabalho e à FAPEMIG pela bolsa concedida à Mônica Jualiani Zavaglia Pereira.

\section{REFERÊNCIASBIBLIOGRÁFICAS}

ABREU, A. de F. B. et al. Utilização da produção de grãos na seleção para resistência ao Colletotrichum lindemuthianum no feijoeiro. Ciência e Agrotecnologia, Lavras, v. 27, n. 2, p. 356-362, mar./abr. 2003.
AMARO, G.B.; ABREU, A. de F.B.; RAMALHO, M.A.P. Phenotypic recurrent selection in the common bean (Phaseolus vulgaris L.) with carioca-type grains for resistance to the fungi Phaeoisariopsis griseola.

Genetics and Molecular Biology, Ribeirão Preto, v.30, n.3, p.584-588, 2007.

ALMEIDA, L. J.; LEITÃO FILHO, H.; MIYASAKA, S. Características do feijão carioca, um novo cultivar. Bragantia, Campinas, v. 30, p. 33-38, 1977.

BALARDIN, R. S.; PASTOR-CORRALES. M. A.; OTOYA, M. M. Resistência de germoplasmas de feijão (Phaseolus vulgaris) a Fusarium oxysporum f.sp. phaseoli.

Fitopatologia Brasileira, v. 15, n. 1, p. 102-103, mar. 1990.

CRAMER, R. A. et al. Characterization of Fusarium oxysporum isolates from common bean and sugar beet using pathogenicity assays and randon-amplified polymorfhic DNA markers. Journal of Phytopathology, v. 151, p. 352-360, June 2003.

CROSS, H.; et al. Inheritance of resistance to Fusarium wilt in two common beans races. Crop Science, v. 40, p. 954-958, July/Aug. 2000.

ECHANDI, E. Amarillamiento del frijol (Phaseolus vulgaris L.) provocado por Fusarium oxysporum f.sp. phaseoli.Turrialba, v.17, n.4, p.409-410, 1967.

ELENA, K.; PAPAS, A. C. Pathogenicity and vegetative compatibility of Fusarium oxysporum f.sp. phaseoli in Greece. Journal of Phytopathology, v. 150, p. 495-499, Sept. 2002.

KNAPP, S. J.; STOUP, W. W.; ROSS, W. M. Exact confidence intervals for heritability on a progeny mean basis. Crop Science, v. 25, n. 1, p. 192-194, Jan./Feb. 1985. 
MATOS, J. W. de; RAMALHO, M. A. P.; ABREU, A. de F. B. Trinta e dois anos do programa de melhoramento do feijoeiro comum em Minas Gerais. Ciência eAgrotecnologia, Lavras, v.31,n.6, p.1749-1754, nov./dez. 2007.

NASCIMENTO, S. R. C.; MARINGONI, A. C.; KUROZAWA, C. Comportamento de variedades e linhagens de feijoeiro ao Fusarium oxysporum f.sp. phaseoli. Fitopatologia Brasileira, v. 20, n. 3, p. 458-463, set. 1995.

PASTOR-CORRALES, M. A.; ABAWI, G. S. Reactions of selected bean germplasms to infection by Fusarium oxysporum f.sp. phaseoli. Plant Disease, v. 71, n. 11, p. 990-993, Nov. 1987.

PEREIRA, M. J. Z.; RAMALHO, M. A. P.; ABREU, A. de F.B. Estratégias para eficiência da seleção de feijoeiro quanto à resistência à murcha-de-fusário. Pesquisa Agropecuária Brasileira, v.43, n.6, p.721-728, jun. 2008.

PEREIRA, M. J. Z.; RAMALHO, M. A. P.; ABREU, A. de F.B. Inheritance of resistance to Fusarium oxysporum f.sp. phaseoli brazilian race 2 in common bean. Scientia Agricola, v.66, n.6, p.788-792, Nov./Dec. 2009.

\section{PIMENTEL-GOMES, F. Curso de estatística} experimental. 13.ed. Piracicaba: Nobel, 1990. 468p.

PIZA, S. M. de T. Patogenicidade de Fusarium oxysporum f.sp. phaseoli e reação de germoplasma de feijoeiro (Phaseolus vulgaris). Summa Phytopathologica, v. 19, n. 3/4, p. 165-167, July/Sept. 1993.

RAGAGNIN, V. A. et al. Avaliação da resistência de isolinhas de feijoeiro ao Colletotrichum lindemuthianum, Uromyces appendiculatus e Phaeoisariopsis griseola. Fitopatologia Brasileira, v. 28, n. 6, p. 591-596, nov./dez. 2003.

RAMALHO, M.A.P.; ABREU, A. de F.B.; SANTOS, J.B. dos. Impact of angular leaf spot on grian yield of common bean lines. Annual Report of Bean Improvement Cooperative, v.50, p.97-98, 2007.

RAMALHO, M. A. P.; SANTOS, J. B. dos; ZIMMERMANN, M. J. de O. Genética quantitativa em plantas autógamas: aplicações ao melhoramento do feijoeiro. Goiânia: UFG 1993. 271 p.
RAVA, C. A.; SARTORATO, A.; COSTA, J. G. C. Reação de genótipos de feijoeiro comum ao Fusarium oxysporum f.sp. phaseoli em casa de vegetação. Fitopatologia Brasileira, v. 21, n. 2, p. 296-300, jun. 1996.

RIBEIRO, C. A. G.; FERRAZ, S. Resistência varietal do feijoeiro (Phaseolus vulgaris L.) a Fusarium oxysporum f sp. phaseoli. Fitopatologia Brasileira, v. 9, p. 37-44, fev. 1984.

RIBEIRO, R. de L. D.; HAGEDORN, D. J. Screening for resistance to and pathogenic specialization of Fusarium oxysporum $\mathrm{f}$ sp. phaseoli, the causal agent of bean yellows. Phytopathology, v. 69, n. 3, p. 272-276, mar. 1979.

ROCHA JÚNIOR, W. C.; SANTOS, J. B.; MENDESCOSTA, M. C. Reação de cultivares e linhagens de feijão à Fusarium oxysporum f. sp. phaseoli. Fitopatologia Brasileira, v. 23, n. 3, p. 407-409, set. 1998.

SALGADO, M. O.; SCHWARTZ, H. F. Physiological specialization and effects of inoculum concentration on Fusarium oxysporum f.sp. phaseoli in common beans. Plant Disease, v. 79, n. 5, p. 492-496, May 1993.

SARTORATO, A.; THUNG, M. Determinação da variabilidade patogênica de Phaeoisariopsis griseola e avaliação da mancha angular. In: TALLER INTERNACIONALSOBRE LA MANCHAANGULAR DELFRIJOL, 1., 2002, Santo Antônio de Goiás, GO. Memórias... Disponível em: <http:// www.cnpaf.embrapa.br/publicacao/seriedocumentos/ doc_132/132_4.htm>.Acesso em: 10 jul. 2007.

\section{SAS/STAT ${ }^{\circledR}$ 8.0 User' Guide. Cary, NC, USA, 1999.}

SENA, M. R. et al. Envolvimento de agricultores no processo seletivo de novas linhagens de feijoeiro. Ciência e Agrotecnologia, v.32, n.2, p.407-412, mar./abr. 2008.

SOUZA JUNIOR, C. L. de. Componentes de variância genética e suas implicações no melhoramento vegetal. Piracicaba: FEALQ, 1989. 134 p.

YOUNG, R. A. et al. Marker-assisted dissection of the oligogenic anthracnose resistance in the common bean cultivar, "G2333". Theoretical and Applied Genetics, v.96, p. 87-94, 1998. 